\title{
CFD Analysis of Auditorium using Ansys Fluent
}

\author{
U. V. Narayana Rao, K. Srinivasa Rao, A. Dattatreya Kumar, G. Yaswanth Kumar, G. Sridhar \\ Babu
}

\begin{abstract}
The primary aspect of any building design and management is heating, ventilation and air conditioning (HVAC). Such systems play very important role in building construction and then the comfort of the occupants of buildings. Hence proper design of such HVAC system is necessary and is essential for efficient and green buildings the HVAC equipment perform the duty of heating and/ or cooling for residential and commercial buildings. Such HVAC system also provide fresh outdoor air to dilute the air contaminants such as odor from occupants of buildings, volatile organic compounds, chemicals etc. Air conditioning equipment is one of the major components in HVAC system. In the project work, an effort has been made to analyses the HVAC system used in seminar halls of which have sitting capacity of $\mathbf{1 0 0}$ people. It is very much essential to have comfortless for people participating in events like seminar, conferences, commercial presentations in seminar hall. Good cooling of seminar hall is essential especially in summer season and moderate warmness is necessary in winter season. In sitting arrangements, the 10 chairs are arranged in 10 rows. The Computational Fluid Dynamic analysis of HVAC system available in seminar hall is carried out by using ANSYS FLUENT software both summer and winter seasons. Parameter studies have been carried out by varying inlet velocity of air in the range 0.1 to $0.5 \mathrm{~m} / \mathrm{s}$. the results have been presented in the form of velocity, pressure and temperature contours. As it is observed that as inlet air velocity increases from 0.1 to $0.5 \mathrm{~m} / \mathrm{s}$. the outlet temperature decreases from 307 to $302 K$.
\end{abstract}

\section{INTRODUCTION}

Now a days heating and ventilation and air conditioning systems (HVAC) are gaining utmost most importance due to expectation of the man and machines to live in comfort zone of specific temperature which is lower than the surrounding temperature (summer season) and higher than surrounding temperature(winter season).

Revised Manuscript Received on 30 July 2019.

* Correspondence Author

U V Narayana Rao*, Civil Engineering Department V R Siddhartha Engineering College, Vijayawada, India.

K Srinivasa Rao, Mechanical Engineering Department V R Siddhartha Engineering College , Vijayawada, India.,

A Dattatreya Kumar, Civil Engineering Department V R Siddhartha Engineering College, Vijayawada, India.

G Yaswanth Kumar Civil Engineering Department V R Siddhartha Engineering College, Vijayawada, India.

G Sridhar Babu., Mechanical Engineering Department V R Siddhartha Engineering College , Vijayawada, India.,

(C) The Authors. Published by Blue Eyes Intelligence Engineering and Sciences Publication (BEIESP). This is an open access article under the CC-BY-NC-ND license http://creativecommons.org/licenses/by-nc-nd/4.0/
Discomfortness in working zone may affect the performance/ work output of a system or a machine or human beings who work for long period of time.

Therefore, the designing of proper HVAC system for individual environment to give the desired comfort zone for better working condition is essential. In such systems the analysis plays important role to know the better working condition based on environmental operating conditions. HVAC system is a common facility for maintaining indoor air quality

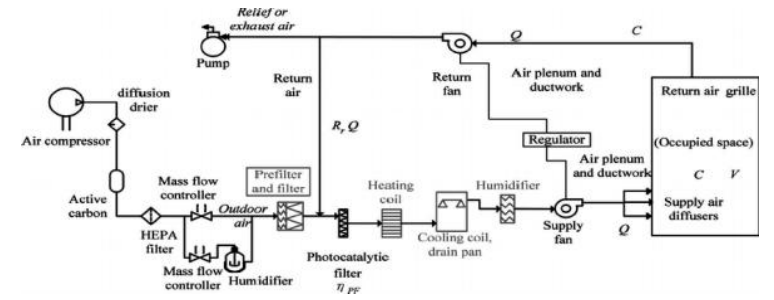

Fig.1. Schematic of the HVAC System

This necessitates the proper designing of buildings in which these systems are housed. A simple schematic diagram of HVAC system is shown in figureTypical HVAC systems have the primary function of controlling the supply air temperature (thermal comfort) and relative humidity (RH). In a HVAC system, the components capable of removing air pollutants contain filters and pre-filters. For particulate control, the mechanical (or electrostatic) filters are used. Some HVAC systems may be equipped with sorbent filters such as active carbon filters to remove gaseous contaminants or vapor emitted from the elements of construction.

\section{Types of HVAC Systems:}

\section{A. Split System for heating and air conditioning}

Split systems are the heating and air conditioning systems of the most classic type. These are the traditional types of HVAC systems where components of the entire system can be found both inside and outside the building.



Fig 2. Heating Split System

Published By:

Blue Eyes Intelligence Engineering \& Sciences Publication 


\section{CFD Analysis of Auditorium using Ansys Fluent}

\section{B. Duct-Free Air Conditioning and Heating System}

A duct-free HVAC provides good facilities for places and areas where duct-free convection systems cannot go.

These systems also complement the existing ducted HVAC system.



Fig.3. Duct-Free Split Heating \& Air Conditioning System

\section{Packaged air conditioning and heating systems}

A bundled HVAC framework is the answer for those homes and workplaces without satisfactory spaces for all the different numerous parts of the split frameworks. Bundled warming and cooling frameworks will deal with kept spaces that range from whole homes to the one-stayed units, across the board bundle.

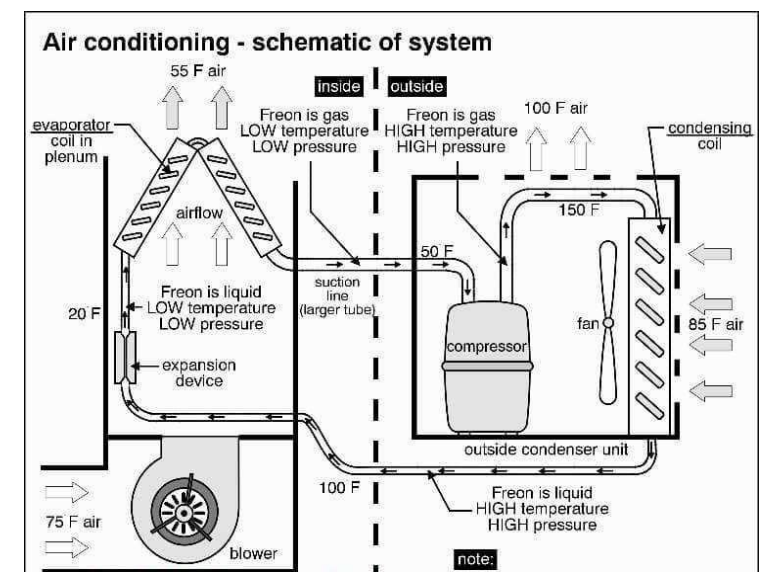

\section{LITERATURE REVIEW}

Sharma et. al. [1] structured a conduit for a cooling framework in a place of business and broke down the significance of pipe plan it makes an effect of framework execution. The above issues featured the requirement for an ideal conduit structure and viable format of the channel. The creators utilized hand count and programming device both for structuring the conduit. They found that the roundabout conduit has a less weight drop than the rectangular pipe.

Whalleyet. al. [2] considered HVAC demonstrating techniques for enormous scale, spatially scattered frameworks. In this paper, they talked about existing procedures and recommendations for the use of novel investigation.

Xuet. al. [3] fielded ponder on the presentation of five warm dispersed frameworks in four huge business structures. They learned about the air spillage from channel, and inferred that the air spillage in enormous business frameworks fluctuated fundamentally from a framework to framework. The vitality misfortune because of a hole can be limited by utilizing conduit fixing and channel protection.

BarisOzerdemet. al. [4] contemplated the vitality misfortune identified with the air spillage by utilizing influence law model. The estimations were made on various sorts of pipe having distinctive breadth. After estimations, they reasoned that the a large portion of the air spillage was from the joint and this air spillage was diminished by about half by utilizing fixing gaskets.

Michal Krajcíket. al. [5] Air dissemination, ventilation effectiveness and warm conditions have been considered tentatively in a reenacted room in a low-vitality building warmed and ventilated by sight-seeing. The estimations were led under various open air conditions, inside warmth gain, rates of air change. Their examination demonstrated that no huge warm distress hazard was influenced by the warm air warming and floor warming frameworks.

Fisk et. al. [6] fielded thinks about in enormous business structures and they examined the viable spillage zones ELAs, air-spillage rates, and conduction warmth increases of pipe frameworks. Air spillage rates were estimated by utilizing distinctive technique and their outcome were analyzed. They found that the air spillage rate shifted from $0 \%$ to $30 \%$. Additionally, heat gains between the cooling curls and the supply registers caused supply air temperatures to increment, by and large, by $0.68^{\circ} \mathrm{C}$ to $28^{\circ} \mathrm{C}$.

Liping Pang et al. [7] decided the proportion of outside air to distribution air. The molded temperature of various kinds of gulfs were structured cautiously to accomplish the high air quality, warm solace and vitality sparing. Moreover, a few analyses were directed and their exhibitions were contrasted and different frameworks. Their outcomes showed that, the improved example keep up high air quality, since it transported all the more natural air straightforwardly to the .breathing zone and flowed it around the chest area of travelers.

Srinivasan et al. [8] picked up an encounter for assessment of air spillages in parts of cooling frameworks by structuring and testing of hole plate-based stream estimating frameworks. The coefficients of release were assessed and contrasted and the Stolz condition which esteem were higher, the deviations being bigger in the low Reynolds number. It was seen that a second-degree polynomial was deficient to relate the weight drop and stream rate.

Huan-RueiShiu et al. [9] The fumes pipe framework was structured utilizing a dynamic programming technique in the semiconductor plant that considered the framework weight balance to be the least life-cycle cost to create channel size and fan limit. Their outcomes demonstrated that the outcome esteem met the channel distance across range necessities. Furthermore, the contrasts among structure and recreation (real activity) were observed to be altogether lower in DPM than in different techniques.

Wanyu R. Chan et al. [10] broke down the air spillage estimations of 134,000 single-family disengaged homes in the US, utilizing standardized spillage.

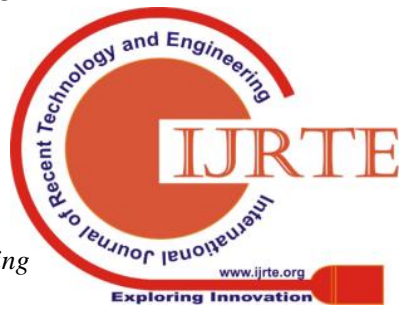


They performed relapse investigations to look at the connection among NL and different house qualities. Their outcomes demonstrated that the relapse model anticipated $90 \%$ of US houses had NL somewhere in the range of 0.22 and 1.95, with a middle of 0.67 .

Dongliang Zhang et al. [11] examined the vitality sparing probability of advanced variable various cooling framework and contrasted with the other the air frameworks with consistent air volume and essential air fan loop framework. Their outcomes uncovered that the vitality sparing of DVM burden condition and this framework was critical when building region was under $20,000 \mathrm{~m}^{2}$.

A. Gallegos-Muñoz et al. [12] examined the impact in the estimations of stream in cooling framework brought about by fitting. They created numerical reenactment utilizing CFD where the Reynolds Averaged Naviere Stokes conditions were tackled through a methodology of limited volume technique utilizing a few choppiness models. Their outcomes showed that the mass stream rate was diminished when no of joints were expanded. Likewise, the work gave data about the conduct of stream estimations made downstream.

IsakKotcioglu et al. [13] discovered an ideal estimation of structure parameters in a rectangular pipe by utilizing Taguchi technique. Their investigation was performed with an improvement procedure to achieve the base weight drop and most extreme warmth exchange. After certain trials they gave an appropriate planned parameter which fulfilled the condition for example less contact drop, most extreme warmth exchange.

Omer Kaynakli et al. [14] gave an audit concentrate to discover monetary warm protection thickness for pipe and pipes with various geometries in different businesses. The motivation behind their investigation was to decide the basic thickness protection for various geometries. The essential outcome, financial investigation strategy, heat exchange technique, advancement method were utilized for correlation. After that the successful parameters of the ideal thickness were analyzed.

TabishAlam et al. [15] contemplated the impact of turbulators for grating trademark and warmth move in air pipes. Turbulators were utilized to improve the exhibition of air radiator and warmth exchanger. The relationship was introduced as far as non-dimensional parameter for contact factor and warmth move in air pipe. Additionally they inspected warmth exchange increment and stream structure in air pipes.

\section{METHODOLOGY}

\section{A. Problem Description:}

A seminar hall center for pg studies is fitted with a HVAC system of blue star company. Its approximate dimensions are 12 X 9 X $3.6 \mathrm{~m}$. Where $12 \mathrm{~m}$ is the total length of the Volume that is designed to analyze $9 \mathrm{~m}$ is the width of the auditorium that is Expanded and 3.6 is the height of the room that is required to design a Volume that is feasible to analyze initially The conditions of Summer are simulated in the fluent i.e., with 45C Temperature as environmental temperature an AC of the 3 ton is Fitted at the either side of the wall i.e., 6 no's Heat generated by 100 people in the auditorium should cooling framework was noteworthy under possibly part

be cooled in order to reduce the internal temperature of the auditorium while considering the Environment as summer similarly the same procedure is followed for winter also. To determine the Pressure Velocity and temperature contours. In general the process of setting up a problem in the FLUENT is Common for most of the case

In preprocessing the description of the problem is understand with suitable criteria or values then the model is designed in either 2D or 3D on Authors interest After completion of the model the Design is the imported into the ANSYS module to modify in a way to setup the design for meshing all the process including meshing and named selections are also done in the Pre processing following are the steps to complete the Preprocessing

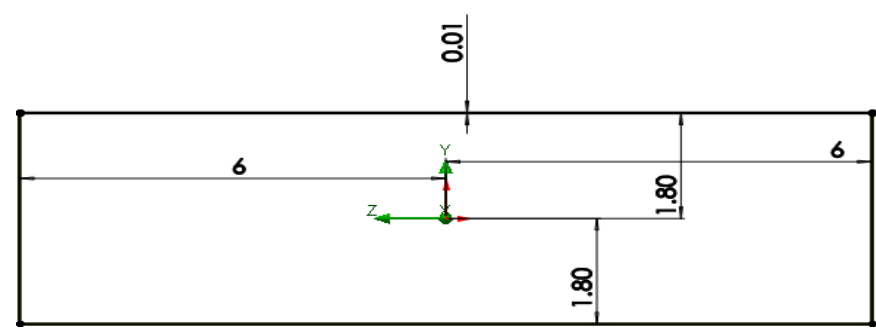

Fig.5. Initial Length and height of the Volume designed in solid works.



Fig. 6 width is added to complete the volume

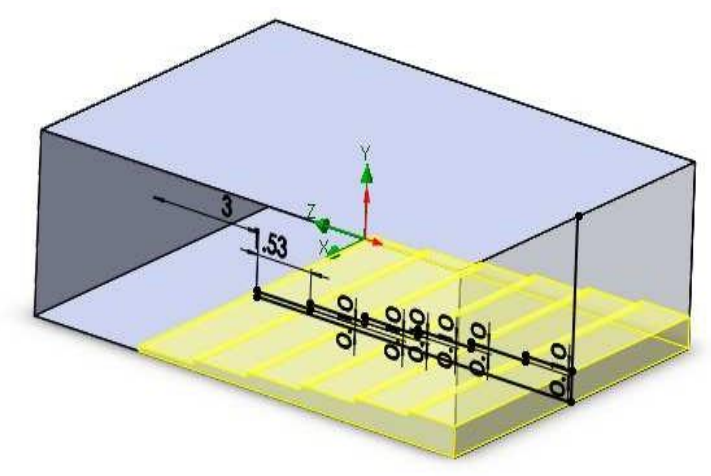

Fig.7 Necessary changes to be done for the volume

Published By: 


\section{CFD Analysis of Auditorium using Ansys Fluent}

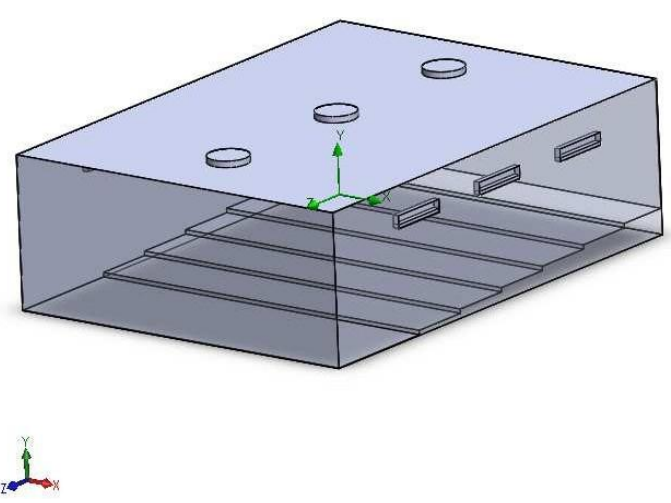

Fig.8 complete model with necessary inlet and outlet ducts

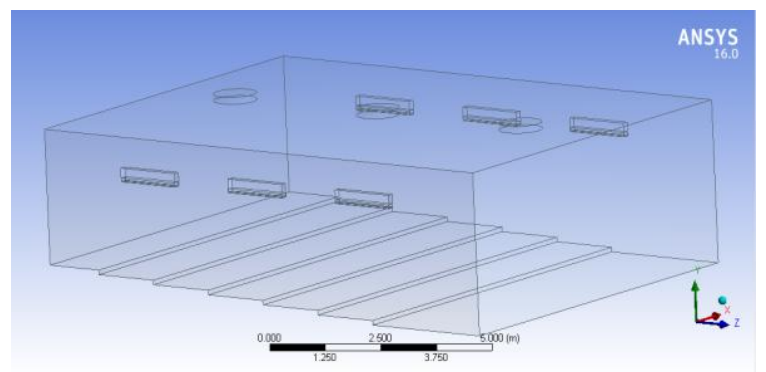

Fig. 9 Imported model for setup and solution on fluent

The Volume Extraction is the Key in all the Problems including HVAC the Empty space that is created in the Computer aided designing is converted in to Volume to generate required Dimensioned volume for the simulation.

\section{B. Meshing}

Meshing is the important aspect in defining the solution a finely discretized mesh will give the better results than Coarsely discretized mesh in general meshing means dividing the large volume to finite set of control volumes which predicts the flow of the in side or outside of the volume the below mesh occurred by performing several mesh methods like tetrahedron and edge sizing to define lowest skewness possible.To decide climate or not our work is worthy that implies amazing cross section and lower quality work we depend on two components to decide such quality Skewness and symmetrical quality Where skewness ranges from 0 to 1 esteems more like 1 is a lower quality components it relies upon the all out number of components that is available in the adequate quality likewise for the symmetrical quality the other way around.



Fig.10 Discretized Domain

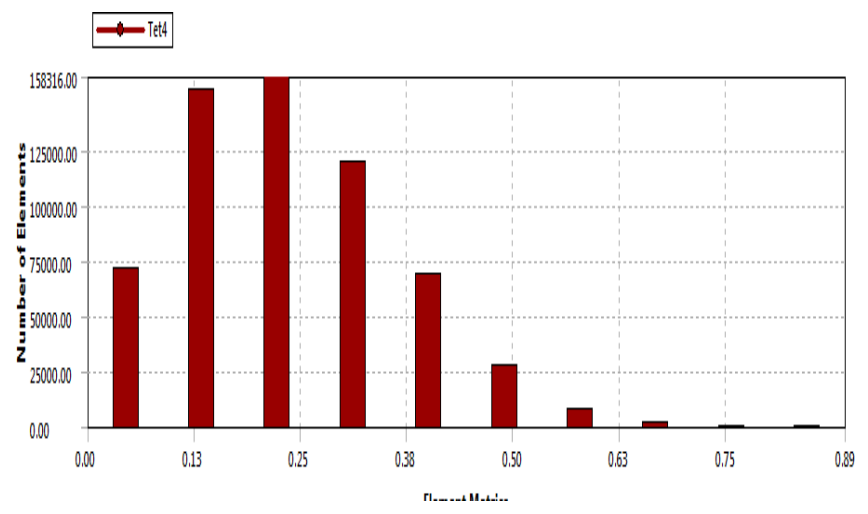

Fig.11 Skewness Factor

The above represented figure is the Skewness of the mesh where u can observe that the most of the Mesh elements are present in the acceptable factor area so we can determine this as a good quality mesh



Fig.12Orthogonal quality

Table 1 Mesh Statistics

\begin{tabular}{|c|c|}
\hline \multicolumn{2}{|c|}{ Statistics } \\
\hline Nodes & 117324 \\
\hline Elements & 609399 \\
\hline Mesh Metric & Orthogonal Quality \\
\hline Min & 0.18685 \\
\hline Max & 0.99732 \\
\hline Average & 0.85557 \\
\hline Standard Deviation & $8.7124 \mathrm{e}-002$ \\
\hline
\end{tabular}

\section{Boundary Conditions:}

Assuming the Required Boundary conditions is key for accurate problem solving by assuming the Realistic conditions We are trying to simulate possible Accurate simulation there Giving the Boundary conditions will play a very important role in solution.Below Mentioned Figure is the representation of the Boundaries that are mentioned in the problem and later we will give the Values for that 


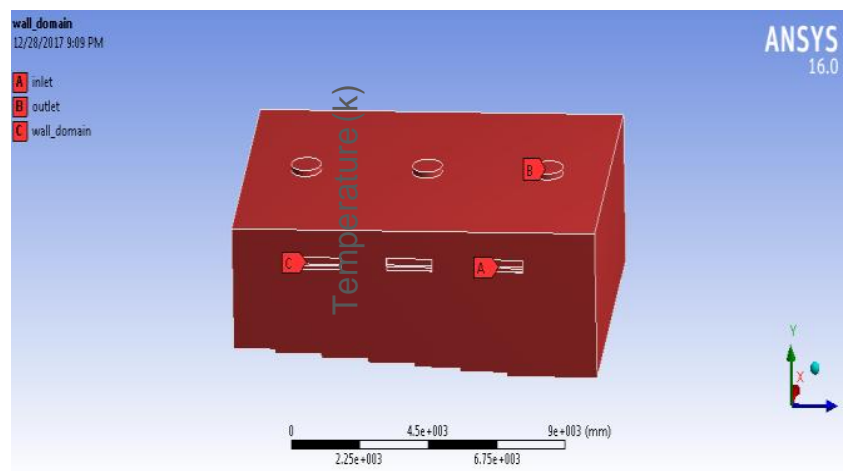

Fig13BoundaryRepresentation using named selections

Where We are assuming that the inlet is from the AC and the wall domain is considered to be Outside environmental temperature i.e., Summer or winter outlet will be the outlet ducts of the system We are assuming in the considered Auditorium 100 members are present according to the literature The temperature will be $300 \mathrm{~K}$ where we are operation the air conditioning at $289 \mathrm{~K}$ and the wall domain temperature is $320 \mathrm{~K}$ at summer and $298 \mathrm{~K}$ at winter as the reviewed environmental temperature by considering there boundary temperatures the Analysis is done in several Velocity inlet cases for $0.1,0.2,0.3,0.4,0.5 \mathrm{~m} / \mathrm{s}$ for both the summer and Winter.

\section{D.Solution Setup}

In order to define the setup it is important to define the physics of the problem in setup the main steps we consider for setting up a problem is in which friction the flow is happening and in which direction The gravity is acting, is the Flow laminar or turbulent Weather the Fluid is Newtonian or non Newtonian to determine these conditions we need to Select some options in the Fluent Setup below is the Step by step process of the Setup

\section{RESULTS AND DISCUSSIONS:}

\section{A. Introduction}

As we discussed in the methodology and abstract the total analysis is done for an auditorium model in summer and winter conditions for different velocity inlet conditions and different outside temperature as per the regional temperature considered in summer and winter. Below are the result contours of different Cases.

\section{Validation:}

\begin{tabular}{|c|c|c|}
\hline $\mathrm{X}(\mathrm{m})$ & K Epsilon realizable & Blay 1992 \\
\hline 0 & 288.16 & 288.16 \\
\hline 0.05 & 297.44 & 296.32 \\
\hline 0.1 & 303.94 & 304.56 \\
\hline 0.15 & 300.41 & 301.66 \\
\hline 0.25 & 297.89 & 298.91 \\
\hline 0.35 & 297.43 & 299.17 \\
\hline 0.5 & 297.29 & 299.01 \\
\hline 0.78 & 296.92 & 297.6 \\
\hline 1.02 & 288.16 & 288 \\
\hline
\end{tabular}

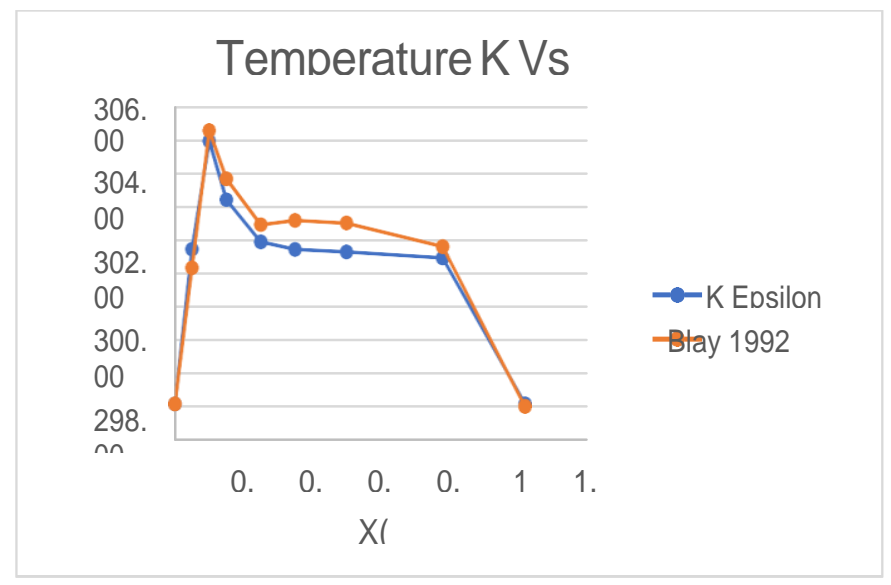

The above Graph represents the temperature Vs Distance X in $\mathrm{m}$ for a Square Cavity with Length $1.04 \mathrm{~m}$ of a mixed convection model proposed by Blay et al in 1992 To get more confidence in our results this validation is proposed
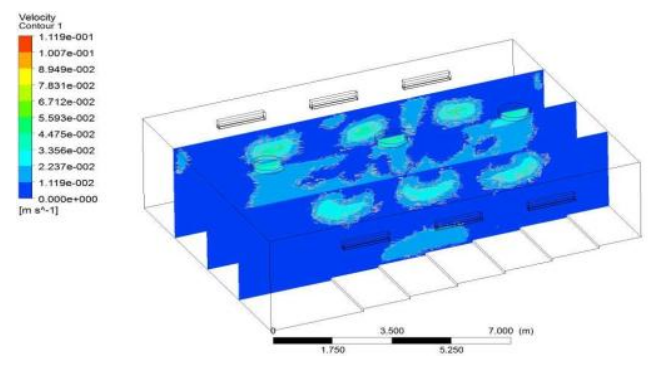

$\underset{\text { ANSYS }}{\text { R16. }}$



Fig 14 Velocity contour of the model at $0.1 \mathrm{~m} / \mathrm{s}$
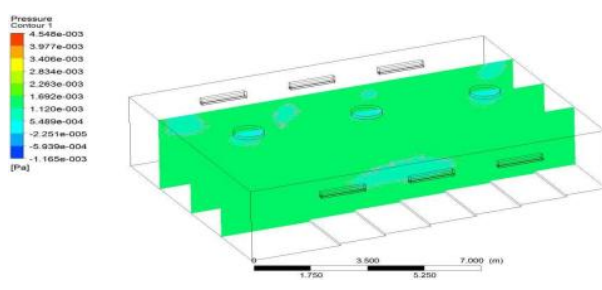

ANSYS
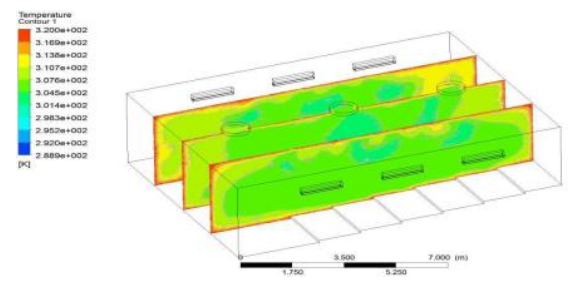

ANSYS

Fig 16 Temperature contour of the model at $0.1 \mathrm{~m} / \mathrm{s}$

B. Analysis of the HVAC model in winter condition:



Fig 17 temperature contour of the model at $0.1 \mathrm{~m} / \mathrm{s}$

Published By: 


\section{CONCLUSIONS}

In the Current work a thorough investigation of heat transfer in HVAC at summer and winter time is carried out. From the Results obtain and plotted Graphs is clear that when the Velocity at the Inlet system increases the Heat transferred to the Fluid decreases it is clear in both summer and winter Times. Whereas an increase in Final Temperature of the winter is observed is is known that there will be the minimum heat transfer of the collected mass of the fluid transferred in to the system. The contours obtained in both summer and winter is showing the area at the corners are showing minimum heat dissipation when compare to the area in between The colored representation is observed clearly to state the conclusion that the temperature at the center of the auditorium is minimum when compare with the total heat dissipation at corners.

\section{REFERENCES}

1. G.S. Sharma and B. Sharma. - Duct designing in air conditioning system and its impact on system performancell. VSRD International Journal oMechanical, Automobile and Production Engineering, Vol. 2 No. 9 November 2012.

2. R. Whalley, A.A.Ameer. - Heating, ventilation and air conditioning system modeling\|. Building and Environment 46 (2011) 643-656.

3. Tengfang T. Xu, Francois R. Carrie, Darryl J Dickerhoff, William J. Fisk.-Performance of thermal distribution systems in large commercial buildingl. Building and Environment 34 (2002) 215-226.

4. Aydin, B.Ozerdem. Air leakage measurement and analysis in duct systems. Energy and Buildings 38 (2006) 207-213.

5. M. Krajcík, A. Simonea, B. W. Olesena. Air distributionand ventilation effectiveness in an occupied room heated by warm airl. Energy and Buildings 5(2012) 94-101.

6. W. J. Fisk, W.Delp, R. Diamond, D. Dickerhoff, R. Levinson, M. Modera, M. Nematollahi, D. Wang. Duct systems in large commercial buildings:physicalcharacterization, air leakage, and heat conduction gains. Energy and Buildings 32 (2000) 109-119.

7. .L. Pang, J. Xu, L. Fang, M. Gong, H. Zhang, Y. Zhang. Evaluation of an improved air distribution system for aircraft cabin. Building and Environment 59 (2013) 145-152

8. K. Srinivasan. Measurement of air leakage in air-handling units and air conditioning ducts. Energy and Buildings 37 (2005) 273-277.

9. O. Kaynakli. Economic thermal insulation thickness for pipes and ducts: A review study. RenewableandSustainableEnergyReviews30 (2014) 184-194.

10. T. Alam, R.P.Saini, J.S.Saini. Heat and flow characteristics of air heater ducts provided with turbulators - A review. Renewable and Sustainable Energy Reviews 31 (2014) 289- 304.

\section{AUTHORS PROFILE}

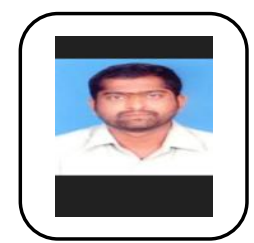

U V Narayana Rao is presently working as an Assistsnt Professor in Civil Engineering Department in V R Siddhartha Engineering College with M.Tech degree and published 7papers into reputed International Journals

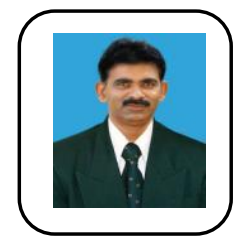

K Srinivasa Rao is currently working as an Assistant Professor in the Mechanical Engineering Department in V R Siddhartha Engineering College with M.Tech Degree and published 10 papers into reputed International Journals.



A Dattatreya Kumar is currently working as an Assistant Professor in the Civill Engineering Department in V R Siddhartha Engineering College with M.Tech Degree and published 4 papers into reputed International Journals .. 